\title{
ANALISIS KOMPARATIF TEGANGAN STATIK PADA FRAME GANESHA ELECTRIC VEHICLES 1.0 GENERASI 1 BERBASIS CONTINOUS VARIABLE TRANSMISSION (CVT) BERBANTUAN SOFTWARE ANSYS 14.5
}

\author{
K. Budarma, K. Rihendra Dantes, G. Widayana \\ Jurusan Pendidikan Teknik Mesin \\ Universitas Pendidikan Ganesha \\ Singaraja, Indonesia \\ e-mail : (budarma_kadek@yahoo.com, rihendra79@gmail.com, \\ gedewidayana@gmail.com)
}

\begin{abstract}
Abstrak
Rangka (frame) merupakan salah satu komponen yang penting dari sepeda motor karena berfungsi sebagai penopang mesin, sistem suspensi dan sistem kelistrikan sehingga menjadi satu kesatuan yang membuat sepeda motor dapat berjalan. Untuk itu, dilakukan analisis tegangan statik pada frame Ganesha electric vehicles 1.0 Generasi 1 yang menggunakan frame Yamaha Nouvo dengan menggunakan software Ansys 14.5 dengan perbandingan pembebanan satu penumpang dan dua penumpang. Tujuan penelitian adalah untuk mengetahui distribusi tegangan serta daerah kritis yang terjadi pada frame. Setelah proses analisis dilakukan, didapatkan tegangan von mises maksimum untuk frame standart dengan satu penumpang sebesar $4,5884 \times 10^{7} \mathrm{~N} / \mathrm{m}^{2}$ dan frame modifikasi sebesar $4,1374 \times 10^{7} \mathrm{~N} / \mathrm{m}^{2}$. Untuk frame standart dengan dua penumpang sebesar $1,0324 \times 10^{8} \mathrm{~N} / \mathrm{m}^{2}$ dan frame modifikasi sebesar $9,3092 \times 10^{7} \mathrm{~N} / \mathrm{m}^{2}$. Faktor keamanan frame standart dengan satu penumpang sebesar 13,52 dan frame modifikasi sebesar 14,99. Untuk frame standart dengan dua penumpang sebesar 6,00 dan frame modifikasi sebesar 6,66.
\end{abstract}

Kata Kunci : Frame, Analisis Tegangan Statik, Ansys 14.5, Tegangan Von Mises, Faktor Keamanan

\begin{abstract}
Frame is one of the important components of the motorcycle because it is functioned as the supporting unit of the machine, suspension system and electricity system to make the motorcycle runs as one complete unit. For that reason, the analysis of the static stress was conducted to the first generation of Ganesha electric vehicles 1.0, which uses the frame of Yamaha Nouvo through Ansys 14.5 software with the comparison of one person weight and two persons weight. The purpose of the research is to know the distribution of the stress and the critical area that occurs at the frame. After the analysis has been conducted, it was found that the stress of the maximum von mises for the standart frame with one weight was $4,5884 \times 10^{7} \mathrm{~N} / \mathrm{m}^{2}$ and the modificated frame was $4,1374 \times 10^{7} \mathrm{~N} / \mathrm{m}^{2}$, for standart frame with two weights was $1,0324 \times 10^{8} \mathrm{~N} / \mathrm{m}^{2}$ and modificated frame was $9,3092 \times 10^{7} \mathrm{~N} / \mathrm{m}^{2}$. The factor of safety with one weight was at the value 13,52 while the modificated one valued 14,99 . For the standart frame with two weights the value was 6,00 while the modificated valued 6,66.
\end{abstract}

Keywords : Frame, The analysis of static stress, Ansys 14.5, Von Mises stress , Factor of safety

\section{PENDAHULUAN}

Rangka (frame) merupakan komponen yang paling penting dari sepeda motor karena berfungsi sebagai penopang mesin, sistem suspensi dan sistem kelistrikan sehingga menjadi satu kesatuan yang membuat sepeda motor dapat berjalan. Oleh karena itu, agar dapat berfungsi sebagaimana mestinya sebuah frame harus kuat dan kokoh sehingga mampu menopang beban dari penumpang, mesin beserta kelengkapannya tanpa 
mengalami kerusakan ataupun perubahan bentuk. Selain itu, frame juga harus ringan agar tidak membebani kerja mesin dan mempunyai nilai fleksibilitas yang berfungsi meredam getaran yang diakibatkan kondisi jalan yang rusak dan oleh mesin. Melihat fungsi frame sangat penting pada sepeda motor, maka perlu diketahui tegangan maksimum yang terjadi pada setiap pembebanan dengan cara melakukan analisis terhadap frame tersebut dengan menggunakan software ansys 14.5. Tujuan penelitian tugas akhir ini adalah untuk mengetahui distribusi tegangan statik yang terjadi.

\section{KAJIAN TEORI}

\subsection{Pengertian Frame}

Frame merupakan komponen terpenting dari sebuah sepeda motor karena berfungsi sebagai penopang mesin, penyangga penumpang atau beban dan menyatukan atau merangkai mesin, sistem suspensi dan sistem kelistrikan menjadi satu kesatuan sepeda motor yang dapat berjalan ${ }^{[8]}$.

\subsection{Jenis Frame}

Frame sepeda motor terdiri dari beberapa jenis, antara lain ${ }^{[8]}$ :

1. Rangka Pelat Baja dan Pipa (Pressed Steel and Tubular)

2. Rangka Pelat Baja (Pressed Steel)

3. Rangka Pipa (Tubular)

4. Rangka Backbone

5. Rangka Diamond

6. Rangka Single Cradle

7. Rangka Double Cradle

8. Rangka Alumunium

\subsection{Baja}

Baja merupakan paduan yang terdiri dari besi, karbon dan unsur lainnya ${ }^{[4]}$. Baja mempunyai keuntungan yang cukup tinggi yaitu kekuatan tariknya yang tinggi antara 300 Mpa sampai 2000 Mpa sehingga membuat struktur dari baja mempunyai ukuran penampang yang lebih kecil jika dibandingkan dengan struktur dari bahan yang lainnya ${ }^{[10]}$.

\subsection{Tegangan (Stress)}

Tegangan atau sering disebut dengan stress dilambangkan dengan $\sigma$ yang memiliki satuan $\mathrm{N} / \mathrm{m}^{2}$. Konsep tegangan dapat diilustrasikan dalam bentuk yang paling mendasar seperti pada sebuah batang prismatis yang diberikan/mengalami gaya aksial ${ }^{[5]}$. Batang prismatis adalah sebuah elemen struktur lurus yang mempunyai penampang konstan di seluruh panjangnya, sedangkan gaya aksial adalah beban yang mempunyai arah yang sama dengan sumbu elemen, sehingga pada batang tersebut akan mengalami tarikan ataupun tekanan.

Tegangan yang terjadi pada suatu benda dapat dirumuskan sebagai berikut :

$$
\sigma=\frac{\mathrm{F}}{\mathrm{A}}
$$

Dimana :

$\sigma=$ Tegangan/gaya persatuan luas $\left(\mathrm{N} / \mathrm{m}^{2}\right)$

$\mathrm{F}=$ Gaya $(\mathrm{N})$

$A=$ Luas Penampang $\left(\mathrm{m}^{2}\right)$

\subsection{Regangan (Strain)}

Regangan atau strain dilambangkan dengan $\varepsilon$. Regangan pada suatu benda terjadi jika benda tersebut mengalami perubahan panjang akibat diberikan beban secara aksial. Sama halnya dengan tegangan, regangan juga mengalami tekanan dan tarikan ${ }^{[5]}$.

Rengangan dapat dirumuskan sebagai berikut :

$$
\varepsilon=\frac{\Delta L}{L}
$$

Dimana :

$\varepsilon=$ Regangan

$\Delta \mathrm{L}=$ Pertambahan panjang $(\mathrm{mm})$

$\mathrm{L}=$ Panjang mula-mula $(\mathrm{mm})$

\subsection{Deformasi}

Benda yang diberikan beban akan mengalami suatu perubahan dari bentuk awalnya, baik yang berupa perubahan bentuk maupun ukuran atau berdeformasi. Bertambahnya ukuran benda akibat mengalami pembebanan disebut dengan perpanjangan atau elongasi. Sebaliknya, jika ukuran benda setelah mendapatkan beban menjadi pendek disebut dengan pemendekan atau konstraksi.

Selama mengalami proses deformasi, benda akan menyerap energi 
sebagai akibat dari adanya gaya yang bekerja sehingga benda tersebut akan mengalami perubahan bentuk dan dimensi. Perubahan bentuk secara fisik pada benda dibagi menjadi dua, yaitu deformasi elastis dan deformasi plastis.

Dimana deformasi elastis bahan sangat ditentukan oleh modulus elastisitas atau yang sering disebut dengan modulus young yang dirumuskan sebagai berikut :

$$
\mathrm{E}=\frac{\sigma}{\varepsilon}
$$

Dimana :

$\mathrm{E}=$ Modulus elastisitas

$\sigma=$ Tegangan $\left(\mathrm{N} / \mathrm{m}^{2}\right)$

$\varepsilon=$ Regangan

\subsection{Teori Von Mises}

Teori kegagalan material ini dikemukakan oleh Von Misses tahun 1913 yang menyatakan bahwa akan terjadi luluh pada benda jika tegangan yang diterima benda tersebut melampaui kekuatan luluh [7]. Teori Von Misses ini sering digunakan untuk memprediksi faktor keamanan dari suatu material pada benda.

Adapun rumus yang digunakan untuk mengetahui faktor keamanan adalah sebagai berikut :

$$
\eta=\frac{s_{y}}{\sigma_{e}}
$$

Dimana :

$\eta=$ Faktor keamanan

$\mathrm{S}_{\mathrm{y}}=$ Tegangan luluh material $\left(\mathrm{N} / \mathrm{m}^{2}\right)$

$\sigma_{\mathrm{e}}=$ Tegangan von misses maksimum $\left(\mathrm{N} / \mathrm{m}^{2}\right)$

\subsection{Ansys 14.5}

Ansys adalah sebuah software yang mampu menyelesaikan persoalanpersoalan elemen dari pemodelan sampai analisis. Ansys ini banyak digunakan untuk membantu penelitian yang berbentuk statis maupun dinamis, analisis struktural, perpindahan panas, dinamika fluida, dan elektromagnetik untuk para engineer.

\subsection{Kerangka Berpikir}

Untuk memecahkan permasalahan yang ada dapat dijelaskan pada fish bone diagram penelitian analisis tegangan statik berikut.

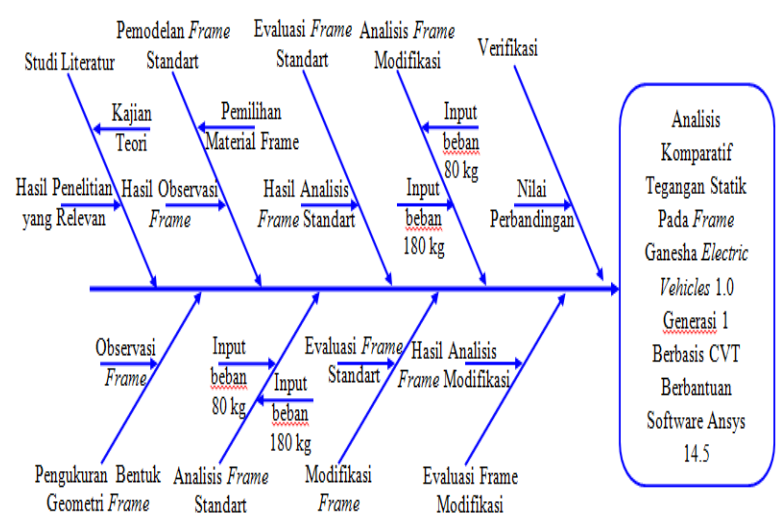

Gambar 2.1. Fish bone Diagram Penelitian Analisis Tegangan Statik

\section{METODE}

Dalam penelitian ini, untuk memperoleh data hasil penelitian dapat dijelaskan seperti pada flow chart penelitian analisis statik pada frame.

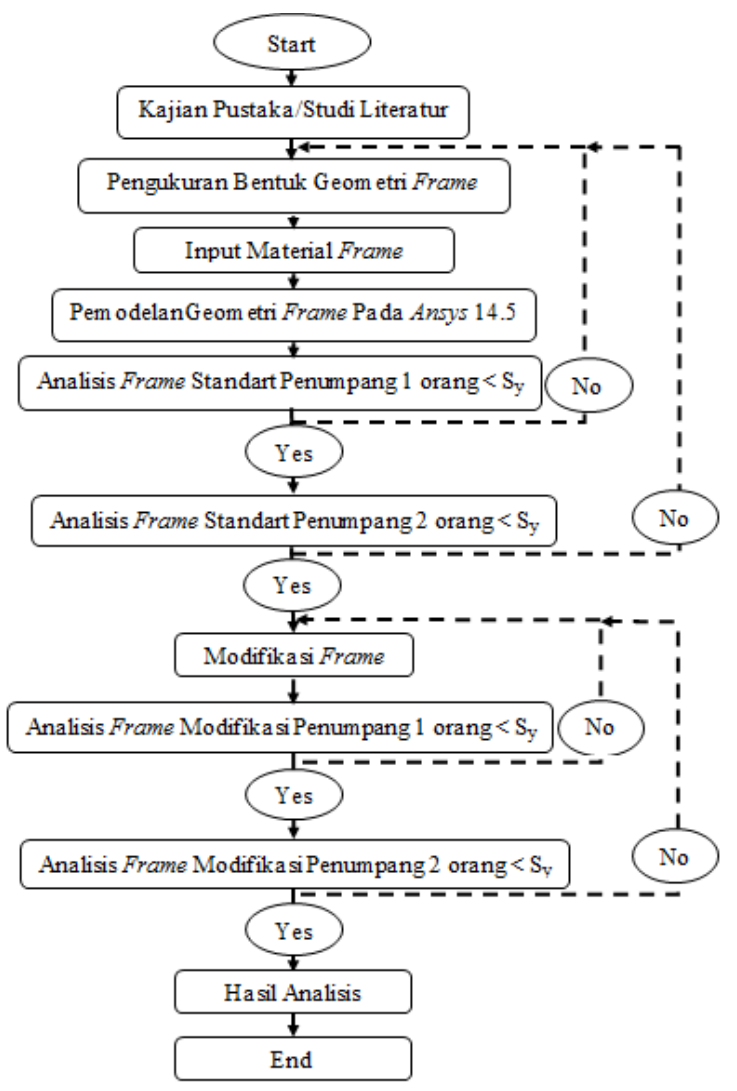

Gambar 3.1.Flow Chart Penelitian Analisis Tegangan Statik Pada Frame 


\section{HASIL DAN PEMBAHASAN}

\subsection{Hasil}

Berikut ini adalah hasil analisis yang telah dilakukan pada frame standart dan frame modifikasi dengan beban 1 orang penumpang dan beban 2 orang penumpang.

\subsubsection{Hasil Analisis Tegangan Statik Frame Standart dengan beban penumpang 1 orang sebesar 80 kg}

Distribusi tegangan statik yang terjadi pada frame standart akibat diberikan beban penumpang 1 orang sebesar $80 \mathrm{~kg}$ bisa dilihat pada gambar 4.1.

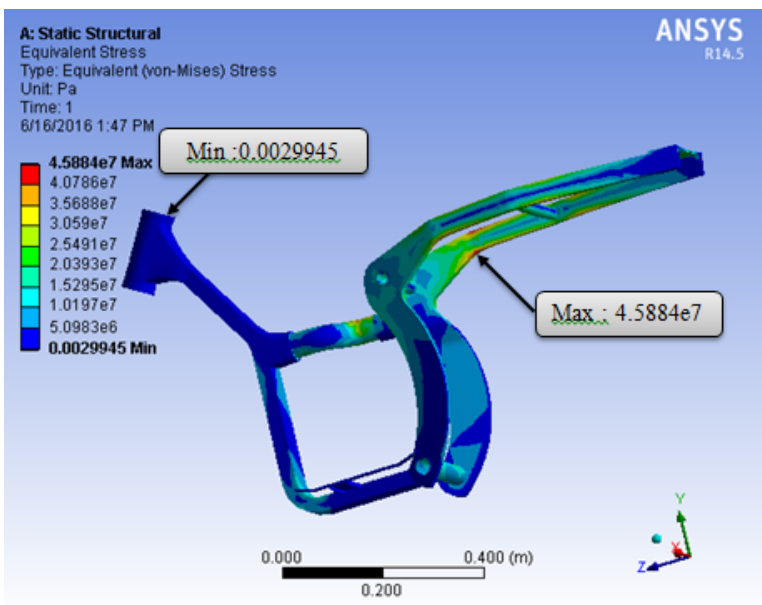

Gambar 4.1. Distribusi Tegangan Statik Frame Standart dengan beban penumpang 1 orang sebesar $80 \mathrm{Kg}$

Hasil tegangan (von misses stress) maksimum ditunjukkan dengan warna merah sebesar $4,5884 \times 10^{7} \mathrm{~N} / \mathrm{m}^{2}$ dan tegangan (von misses stress) minimum ditunjukkan dengan warna biru sebesar $0,0029945 \mathrm{~N} / \mathrm{m}^{2}$ dengan beban yang diberikan sebesar $80 \mathrm{~kg}$. Maka berdasarkan tegangan luluh material yang digunakan yaitu Carbon Steel AISI 1044 sebesar 6,204 $x 10^{8} \quad \mathrm{~N} / \mathrm{m}^{2}$ dapat dipastikan struktur tersebut mampu menahan beban yang diberikan.

Dari hasil analisis, dapat dicari faktor keamanan (factor of safety) dari frame standart yang menerima beban penumpang 1 orang sebesar $80 \mathrm{~kg}$ yang dapat dirumuskan sebagai berikut.

$$
\begin{aligned}
\eta & =\frac{S_{y}}{\sigma_{e}} \\
& =\frac{6,204 \times 10^{8} \mathrm{~N} / \mathrm{m}^{2}}{4,5884 \times 10^{7} \mathrm{~N} / \mathrm{m}^{2}} \\
& =13,52
\end{aligned}
$$

\subsubsection{Hasil Analisis Tegangan Statik Frame Standart dengan beban penumpang 2 orang sebesar $180 \mathrm{Kg}$}

Distribusi tegangan Statik yang terjadi pada frame standart akibat diberikan beban penumpang 2 orang sebesar $180 \mathrm{~kg}$ bisa dilihat pada gambar 4.2.

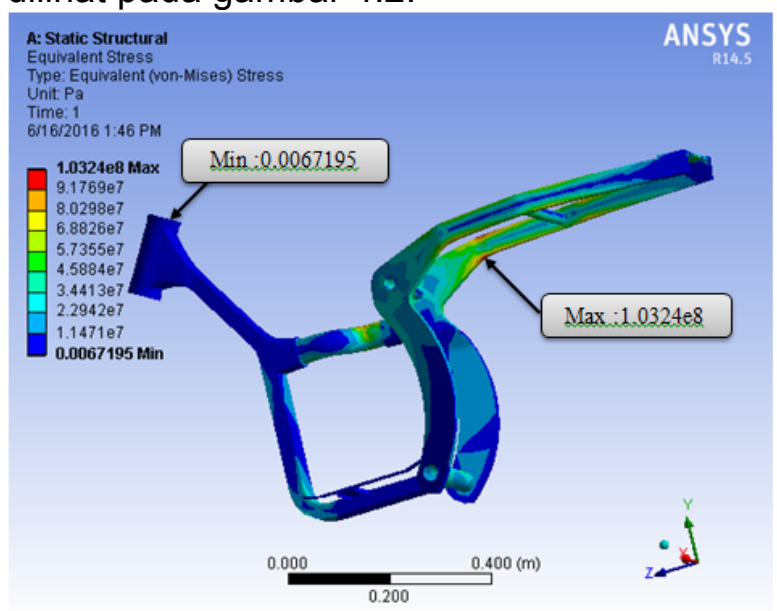

Gambar 4.2. Distribusi Tegangan Statik Frame Standart dengan beban penumpang 2 orang sebesar $180 \mathrm{Kg}$

Hasil tegangan (von misses stress) maksimum ditunjukkan dengan warna merah sebesar $1,0324 \times 10^{8} \mathrm{~N} / \mathrm{m}^{2}$ dan tegangan (von misses stress) minimum ditunjukkan dengan warna biru sebesar $0,0067195 \mathrm{~N} / \mathrm{m}^{2}$ dengan beban yang diberikan sebesar $180 \mathrm{~kg}$. Maka berdasarkan tegangan luluh material yang digunakan yaitu Carbon Steel AISI 1044 sebesar $6,204 \times 10^{8} \mathrm{~N} / \mathrm{m}^{2}$ dapat dipastikan struktur tersebut mampu menahan beban yang diberikan.

Dari hasil analisis, dapat dicari faktor keamanan (factor of safety) dari frame standart yang menerima beban penumpang 2 orang sebesar $180 \mathrm{~kg}$ yang dapat dirumuskan sebagai berikut. 


$$
\begin{aligned}
\eta & =\frac{\mathrm{S}_{\mathrm{y}}}{\sigma_{\mathrm{e}}} \\
& =\frac{6,204 \times 10^{8} \mathrm{~N} / \mathrm{m}^{2}}{1,0324 \times 10^{8} \mathrm{~N} / \mathrm{m}^{2}} \\
& =6,00
\end{aligned}
$$

\subsubsection{Hasil Analisis Tegangan Statik Frame Modifikasi dengan beban penumpang 1 orang sebesar $80 \mathrm{Kg}$}

Distribusi tegangan statik yang terjadi pada frame modifikasi akibat diberikan beban penumpang 1 orang sebesar $80 \mathrm{~kg}$ bisa dilihat pada gambar 4.3.

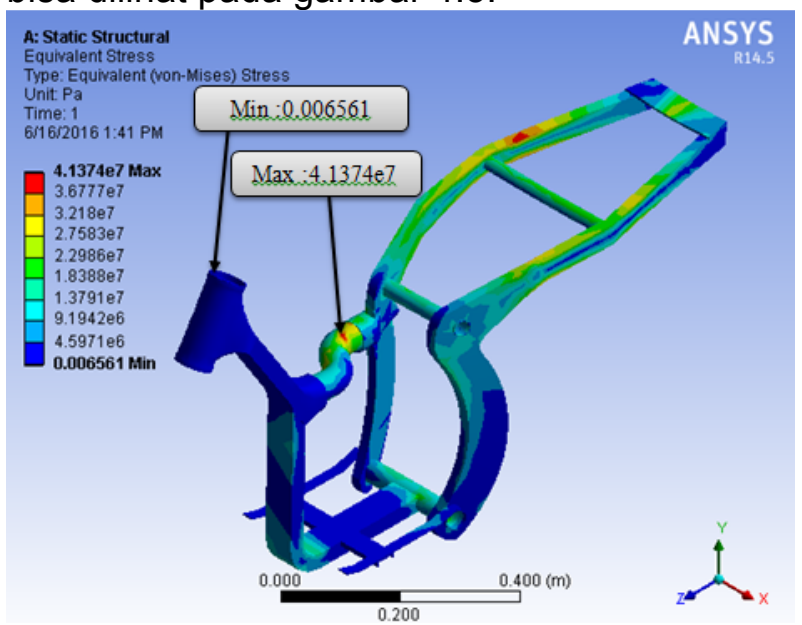

Gambar 4.3. Distribusi Tegangan Statik

Frame Modifikasi dengan beban penumpang 1 orang sebesar $180 \mathrm{Kg}$

Hasil tegangan (von misses stress) maksimum ditunjukkan dengan warna merah sebesar $4,1374 \times 10^{7} \mathrm{~N} / \mathrm{m}^{2}$ dan tegangan (von misses stress) minimum ditunjukkan dengan warna biru sebesar $0,006561 \mathrm{~N} / \mathrm{m}^{2}$ dengan beban yang diberikan sebesar $80 \mathrm{~kg}$. Maka berdasarkan tegangan luluh material yang digunakan yaitu Carbon Steel AISI 1044 sebesar 6,204 $x 10^{8} \quad \mathrm{~N} / \mathrm{m}^{2}$ dapat dipastikan struktur tersebut mampu menahan beban yang diberikan.

Dari hasil analisis, dapat dicari faktor keamanan (factor of safety) dari frame modifikasi yang menerima beban penumpang 1 orang sebesar $80 \mathrm{~kg}$ yang dapat dirumuskan sebagai berikut.

$$
\begin{aligned}
\eta & =\frac{S_{y}}{\sigma_{e}} \\
& =\frac{6,204 \times 10^{8} \mathrm{~N} / \mathrm{m}^{2}}{4,1374 \times 10^{7} \mathrm{~N} / \mathrm{m}^{2}} \\
& =14,99
\end{aligned}
$$

\subsubsection{Hasil Analisis Tegangan Statik Frame Modifikasi dengan beban penumpang 2 orang sebesar $180 \mathrm{Kg}$}

Distribusi tegangan statik yang terjadi pada frame modifikasi akibat diberikan beban penumpang 2 orang sebesar $180 \mathrm{~kg}$ bisa dilihat pada gambar 4.4.

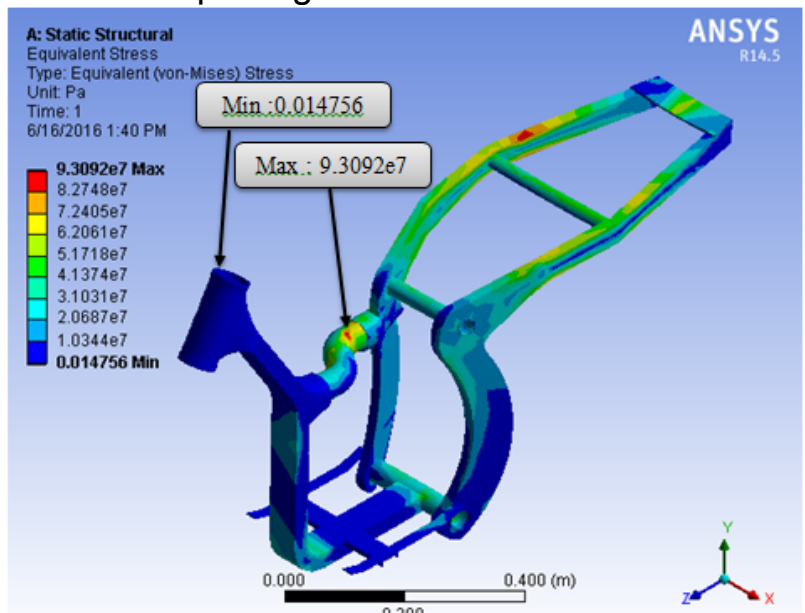

Gambar 4.4. Distribusi Tegangan Statik Frame Modifikasi dengan beban penumpang 2 orang sebesar $180 \mathrm{Kg}$

Hasil tegangan (von misses stress) maksimum ditunjukkan dengan warna merah sebesar $9,3092 \times 10^{7} \mathrm{~N} / \mathrm{m}^{2}$ dan tegangan (von misses stress) minimum ditunjukkan dengan warna biru sebesar $0,014756 \mathrm{~N} / \mathrm{m}^{2}$ dengan beban yang diberikan sebesar $180 \mathrm{~kg}$. Maka berdasarkan tegangan luluh material yang digunakan yaitu Carbon Steel AISI 1044 sebesar $6,204 \times 10^{8} \mathrm{~N} / \mathrm{m}^{2}$ dapat dipastikan struktur tersebut mampu menahan beban yang diberikan.

Dari hasil analisis, dapat dicari faktor keamanan (factor of safety) dari frame modifikasi yang menerima beban penumpang 2 orang sebesar $180 \mathrm{~kg}$ yang dapat dirumuskan sebagai berikut. 


$$
\begin{aligned}
\eta & =\frac{S_{y}}{\sigma_{e}} \\
& =\frac{6,204 \times 10^{8} \mathrm{~N} / \mathrm{m}^{2}}{9,3092 \times 10^{7} \mathrm{~N} / \mathrm{m}^{2}} \\
& =6,66
\end{aligned}
$$

\subsection{Pembahasan Komparatif Frame Standart dan Frame Modifikasi}

\subsubsection{Komparatif Maksimum Frame sta Frame Modifikasi}

Komparatif Tegangan Maksimum Frame Standart dan Frame Modifikasi

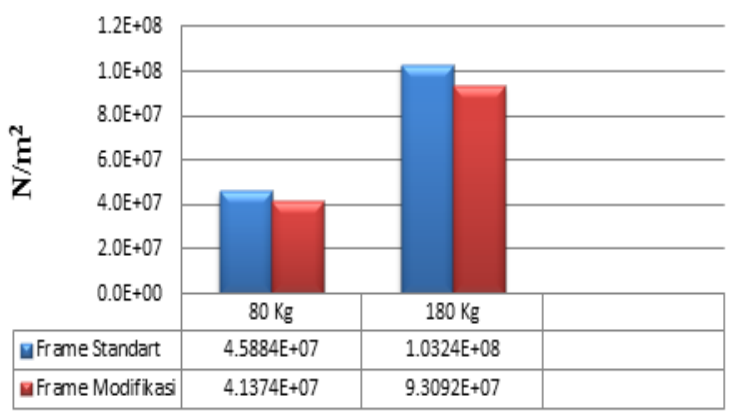

Grafik 4.1. Komparatif Tegangan Maksimum Frame Standart dan Frame Modifikasi

Dari grafik 4.1. diketahui bahwa setelah frame standart dan frame modifikasi dianalisis dengan beban penumpang sebesar $80 \mathrm{~kg}$ dan $180 \mathrm{~kg}$. Hasil tegangan maksimum pada frame standart mengalami penurunan setelah mengalami modifikasi yaitu sebesar $9,82 \%$ untuk beban $80 \mathrm{~kg}$ dan $9,82 \%$ untuk beban $180 \mathrm{~kg}$. Semakin kecil nilai tegangan yang didapat maka kekuatan frame juga semakin baik.

\subsubsection{Komparatif Tegangan Minimum Frame Standart dan Frame Modifikasi}

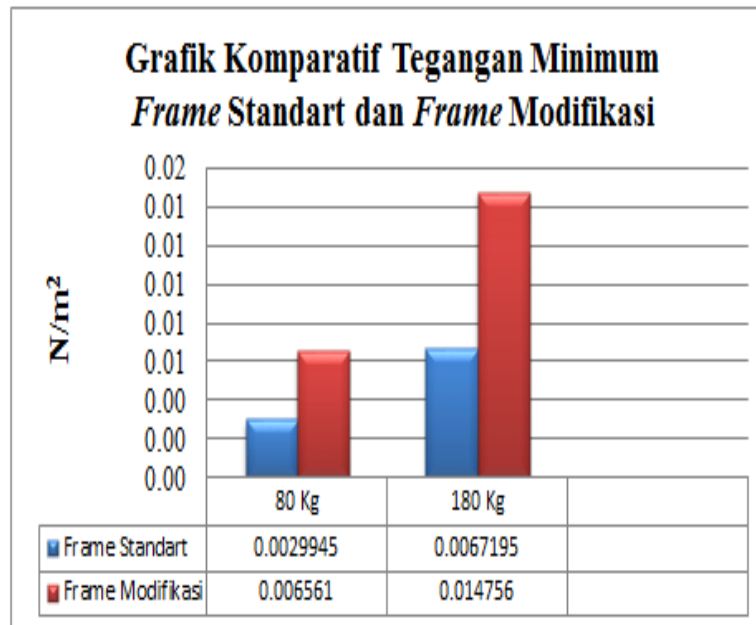

Grafik 4.2. Komparatif Tegangan Minimum Frame Standart dan Frame Modifikasi

Dari grafik 4.2. diketahui bahwa setelah frame standart dan frame modifikasi dianalisis dengan beban penumpang sebesar $80 \mathrm{~kg}$ dan $180 \mathrm{~kg}$. Hasil tegangan minimum pada frame standart mengalami peningkatan setelah mengalami modifikasi yaitu sebesar $54,35 \%$ untuk beban $80 \mathrm{~kg}$ dan 54,45 \% untuk beban $180 \mathrm{~kg}$. Peningkatan ini diakibatkan karena peralihan tegangan maksimum yang terjadi. Dimana yang tadinya pada dudukan penumpang sebelah kanan beralih pada pipa penghubung setelah dimodifikasi, sehingga membuat tegangan minimum menjadi meningkat.

\subsubsection{Komparatif Factor of safety}

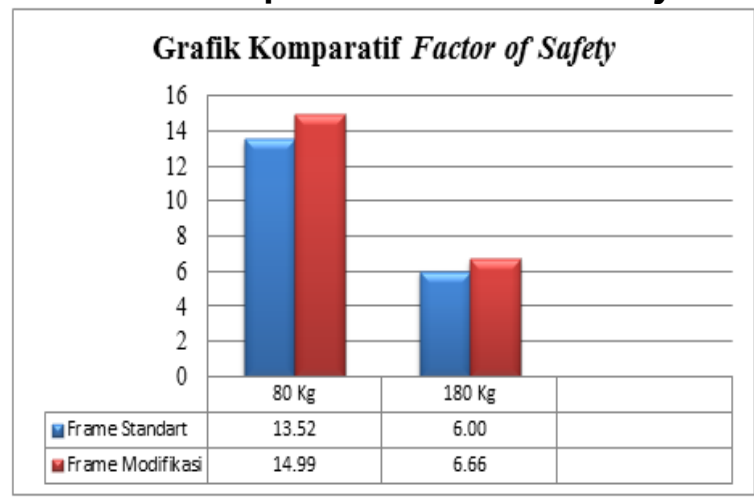

Grafik 4.3. Komparatif Factor of safety

Dari grafik 4.3. diketahui bahwa setelah frame standart dan frame modifikasi dianalisis dengan beban penumpang 
sebesar $80 \mathrm{~kg}$ dan $180 \mathrm{~kg}$. Faktor keamanan (factor of safety) pada frame standart mengalami peningkatan setelah mengalami modifikasi yaitu sebesar 9,80\% untuk beban $80 \mathrm{~kg}$ dan 9,90\% untuk beban $180 \mathrm{~kg}$. Semakin besar faktor keamanan (factor of safety) yang didapat maka kekuatan frame juga semakin baik.

\section{PENUTUP}

Berdasarkan hasil analisis dengan menggunakan software Ansys 14.5 pada frame standart dan frame modifikasi diperoleh kesimpulan sebagai berikut :

1. Tegangan yang dihasilkan dari beban penumpang 1 orang sebesar $80 \mathrm{~kg}$ terhadap frame standart yaitu tegangan maksimum sebesar $4,5884 \times 10^{7} \mathrm{~N} / \mathrm{m}^{2}$ dan tegangan minimum sebesar $0,0029945 \mathrm{~N} / \mathrm{m}^{2}$, serta didapatkan faktor keamanan (factor of safety) sebesar 13,52.

2. Tegangan yang dihasilkan dari beban penumpang 2 orang sebesar $180 \mathrm{~kg}$ terhadap frame standart yaitu tegangan maksimum sebesar $1,0324 \times 10^{8} \mathrm{~N} / \mathrm{m}^{2}$ dan tegangan minimum sebesar $0,0067195 \mathrm{~N} / \mathrm{m}^{2}$, serta didapatkan faktor keamanan (factor of safety) sebesar 6,00.

3. Tegangan yang dihasilkan dari beban penumpang 1 orang sebesar $80 \mathrm{~kg}$ terhadap frame modifikasi yaitu tegangan maksimum sebesar $4,1374 \times 10^{7} \mathrm{~N} / \mathrm{m}^{2}$ dan tegangan minimum sebesar $0,006561 \mathrm{~N} / \mathrm{m}^{2}$, serta didapatkan faktor keamanan (factor of safety) sebesar 14,99.

4. Tegangan yang dihasilkan dari beban penumpang 2 orang sebesar $180 \mathrm{~kg}$ terhadap frame modifikasi yaitu tegangan maksimum sebesar $9,3092 \times 10^{7} \mathrm{~N} / \mathrm{m}^{2}$ dan tegangan minimum sebesar $0,014756 \mathrm{~N} / \mathrm{m}^{2}$, serta didapatkan faktor keamanan (factor of safety) sebesar 6,66.

5. Selain itu, dari hasil analisis yang telah dilakukan didapatkan kesimpulan khusus yaitu frame hasil modifikasi lebih baik daripada frame standart, hal ini terbukti dari penurunan tegangan maksimum yang dialami frame standart setelah dimodifikasi, meskipun terjadi peningkatan pada tegangan minimum yang dikarenanakan terjadinya peralihan tegangan setelah frame mengalami modifikasi. Tidak hanya itu, juga terjadi peningkatan faktor keamanan yaitu sebesar $9,80 \%$ untuk beban $80 \mathrm{~kg}$ dan $9,90 \%$ untuk beban $180 \mathrm{~kg}$.

\section{DAFTAR PUSTAKA}

[1] Berata, Wayan. Diktat Elemen Mesin I. Fakultas Teknologi Industri Institut Teknologi Sepuluh Nopember : Jurusan Teknik Mesin.

[2] Fauzi, Helmi. 2013. "Analisis Tegangan Pada Frame Mobil Listrik Sinosi Menggunakan Metode Elemen Hingga". Tugas Akhir (tidak diterbitkan). Jurusan Teknik Mesin, Universitas Jember.

[3] Firmansyah. 2012. "Analisis Statik Rangka Motor Hybrid Menggunakan Software Catia V5". Tugas Akhir (tidak diterbitkan).Jurusan Teknik Mesin, Universitas Gunadarma.

[4] Joko Prasetyo, Apri. 2010. "Aplikasi Metode Elemen Hingga (MEH) Pada Struktur Rib Bodi Angkutan Publik. Jurusan Teknik Mesin Fakultas Teknik, Universitas Sebelas Maret.

[5] Mulyati. "Bahan Ajar Mekanika Bahan" Tegangan dan Regangan. Pertemuan I,II,III, hIm 1-20.

[6] Nurfauziawati, Nova. 2010. Laporan Praktikum Fisika Dasar Modul 4 Modulus Elastisitas. Universitas Padjadjaran : Jurusan Teknologi Industri Pangan.

[7] Santoso, Puguh. 2014. "Analisis Tegangan Statik Pada Rangka Sepeda Motor Jenis Matic Menggunakan Software Catia P3 V5R14". Tugas Akhir (tidak diterbitkan). Jurusan Teknik Mesin, Univertitas Gunadarma.

[8] Setya Nugraha, Beni. 2005. Chasis Sepeda Motor. Fakultas Teknik UNY : Jurusan Pendidikan Teknik Otomotif

[9] Studi Perancangan dan Rekayasa Sistem Jurusan Teknik Mesin Fakultas Teknik Universitas Brawijaya. Modul Finite Element Analysis. 
[10]Willy Chandra, Maha. 2014. "Aplikasi Finite Elemen Analysis Pada Struktur Rib Bodi Angkutan Publik". Tugas Akhir (tidak diterbitkan). Departemen Teknik Mesin, Fakultas Teknik Universitas Indonesia.

[11]Situs internet :

https://id.wikipedia.org/wiki/Yamaha_Nouvo 